\title{
LA MÚSICA, ¿ARTE, FÍSICA O MATEMÁTICAS?
}

\section{THE MUSIC, ART, PHYSICS OR MATH?}

José Antonio Martínez Pons: Departamento de Química Analítica e Ingeniería Química. Universidad de Alcalá de Henares. Madrid (España) joseantonio.martines@uah.es

\section{CURRÍCULUM VITAE}

Licenciado en Ciencias Físicas (Geofísica) por la Universidad Complutense de Madrid (España) y en Ciencias Químicas (Química física) por la UNED (España). Doctor por la Universidad de Alcalá de Henares (España) en el año 2000. Profesor de la Universidad de Alcalá de Henares en el área de Química analítica e Ingeniería química.

\section{RESUMEN}

La relación entre la ciencia y la música y entre los científicos y el arte viene de muy antiguo. Pitágoras estableció una relación entre el largo de la cuerda de la lira y las notas musicales y ahí empezó la relación entre las matemáticas y la música. En esta relación hay varios nombres que destacar, como Galileo, Kepler, Mozart, o J.S. Bach. Hay además muchos grandes músicos con formación científica. Pero también viceversa: el científico Max Born era un virtuoso del piano. Veamos más casos en este artículo y una reflexión al respecto de la relación entre la música y las artes, la física o las matemáticas. 


\title{
PALABRAS CLAVE
}

Ciencia - Música - Relación - Matemáticas

\begin{abstract}
The relationship between music and science and between science and art is very old. Pythagoras established a relationship between the length of the string of the lyre and musical notes, and there began the relationship between mathematics and music. In this regard there are several names that stand out, like Galileo, Kepler, Mozart, and JS Bach. There are also many great musicians with scientific training. But conversely, the scientist Max Born was a piano virtuoso. See more cases in this article and thinking about the relationship between music and the arts, physics or mathematics.
\end{abstract}

\section{KEY WORDS}

Science - Music - Relationship - Mathematics

\section{TEXTO:}

Desde muy antiguo ha existido una gran ligazón entre la ciencia y la música y entre los científicos y este arte; no en balde para muchos es la más matemática de las artes y por supuesto, la más física. Basta con pasar por un osciloscopio una melodía de Mozart o un fragmento rokero y comparar. No hablo ya de calcularle la entropía de Kolmogorov, porque no quiero ser responsable de que algún ordenador salga echando humo (con el segundo fragmento, por supuesto, en Mozart el orden y la armonía son consustanciales). 
La escuela pitagórica estableció una relación entre el largo de la cuerda de la lira y las notas musicales y ahí empezó el maridaje entre las matemáticas y la música.

El padre de Galileo Galilei, Vincenzo, era un músico notable y el gusto y el conocimiento se observa en la obra de Galileo.

Kepler hablaba de la melodía de las estrellas, incluso es posible encontrar la partitura, que desde luego no tiene nada que ver con la célebre suite "los Planetas" de Gustav Holts, por otra parte tan utilizada como música de fondo de películas y series. (En mis recuerdos, el "Diego Valor" radiofónico de mi infancia, con "Marte el guerrero" o más reciente, el Pequeño Cid de Televisión que también recurría a la obra del compositor inglés.

De Newton no consta que fuera especialmente melómano, es más, más bien parece lo contrario, por una vez que asistió a la ópera, parece que en el tercer acto se aburrió tanto que abandonó el teatro y después de asistir a un concierto de clavicordio, interpretado nada menos que por el gran G.F. Andel (1685-1759), no se le ocurrió otro comentario que elogiar su agilidad de manos. Sin embargo, pese a su escasa sensibilidad dedicó un gran esfuerzo al estudio de la armonía musical. Ello es perfectamente comprensible dentro la mentalidad de Sir Isaac ya que él era pitagórico y pensaba que sus descubrimientos eran sólo una parte de un orden superior. En suma, el cosmos era orden y armonía y, por tanto, a la música sólo se podía llegar con oído matemático. En este sentido se esforzó en encontrar una relación numérica entre los tonos musicales.

Hasta el renacimiento se utilizaba la escala pitagórica que tenía un fallo fundamental debido a la incompatibilidad de las consonancias simples, así por ejemplo, si una octava tiene una relación de frecuencia de 2 a 1 y una quinta perfecta de 3 a 2, un intervalo de siete octavas deberá tener una relación de $27=128$ y doce quintas, 
$(3 / 2) 12=129,7$, sin embargo, los intervalos son equivalentes, luego la relación debe ser la misma. Este problema que no es importante en la música homofónica, si lo es en la polifónica. Se propuso entonces otra escala de entonación justa, pero entonces las relaciones no podían expresarse en relaciones de números enteros. Afortunadamente en 1590 aparecieron las fracciones decimales y en 1614 los logaritmos, con ellos Newton estableció una unidad normalizada de medida de intervalos, el semitono bien temperado, que correspondía a una relación de frecuencia de 21/12 a 1, muy aproximadamente 1,06 a 1, anticipándose a la escala moderna que divide la octava en 1200 unidades y doce semitonos correspondiendo a cada semitono 100 unidades.

En el fondo Newton pensaba que su ley de gravitación universal debía ser consecuencia de la asociación armoniosa entre la música celestial, debida a la relación entre las distancias al Sol de los planetas y los sonidos de una cuerda vibrante. Esta relación, pensaba, no podía haber pasado por alto a los antiguos (los famosos "Gigantes" con mayúscula, a quienes tanto reconocía deber, en contraposición a Hooke que era pequeño y canijo, casi un enano, a quien no debía nada) y así en la primera edición de sus principia afirma que Pitágoras ya la conocía al haber encontrado una relación semejante, de cuadrado inverso entre la frecuencia de la cuerda y la tensión.

Conviene recordar que, por estos tiempos, el Maestro J.S. Bach (1685-1750) compone, entre otras, "El clave bien temperado" y no falta demasiado para que W. A. Mozart (1756-1795), del que he leído no era lego en cálculo infinitesimal, recién descubierto, hiciera del pentagrama campo de todas sus diabluras.

Se podría seguir por el camino de la matemática y la música que podría llevarnos muy lejos: impresionismo, dodecafonismo y música serial, música estocástica, 
electroacústica, fractales en la música y demás engendros modernos, pero no creo que sea lugar, ni yo tengo conocimientos suficientes, así que aligeremos.

Como dije antes, es muy común entre los científicos ser aficionados a la música, no en balde la música es la más matemática de todas las artes.

Hay muchos grandes músicos con sólida formación científica, por ejemplo el gran tenor canario Alfredo Kraus era ingeniero industrial, como también lo era el compositor levantino Oscar Esplá. Franck Martín, compositor suizo casi contemporáneo y décimo hijo de un pastor calvinista, había recibido una sólida formación físico- matemática que se detecta en su obra.

Viceversa, tanto Werner Heisenberg como Max Born eran virtuosos del piano. El primero era capaz de trabajar hasta las tantas con algún doctorando y después relajarse tocando a cuatro manos... a J.S. Bach (como no) y Albert Einstein tocaba el violín hasta el extremo de llegar a formar cuarteto, entre otros, con Gaspar Cassadó, célebre violonchelista catalán. También las aficiones de Einstein iban por el cantor de Leipzig. Es curioso que el músico "moderno" norteamericano J.P. Glass tenga una obra llamada "Einstein en la playa", en mis cortas luces musicales dudo que el padre de la teoría de la relatividad soportará más de tres, llamémosles, compases de tal obra.

El compositor ruso Alexandr Borodin, hijo bastardo de un noble georgiano, autor entre otras obras de la ópera "El príncipe Igor", cuartetos, sinfonías etc, estudió medicina, pero no soportaba la visón de la sangre, por lo que su actividad científica se dirigió sobre todo a la investigación en química orgánica. Era amigo de D. I. Mendeleiev -sí el de la "tabla periódica"-, con quien realizo un largo viaje por Italia. 
Borodin era además militar, general del ejército del Zar y sumamente despistado. Una tarde tenía audiencia con el zar de todas las Rusias, de modo que se vistió con el uniforme de gran gala, se emperifolló y se colocó las condecoraciones en el pecho de la casaca. Bajó la escalera y fue a montarse en su coche, por supuesto de caballos. Ya tenía un pie a bordo, cuando su asistente le sujetó por el brazo:

- Mi general

- ¿Qué ocurre?

- Así no puede ir a ver al Zar.

- Cómo no puedo ir si llevo mi mejor uniforme.

- Sí señor, pero se ha olvidado de ponerse los pantalones.

El matemático alemán Weierstrass era una excepción, detestaba la música. Aparte era muy amigo de Bunsen, el inventor del mechero de su nombre y autor de una frase que debería grabarse en la puerta de todas las facultades de Química:

"El químico que no es físico no es nada en absoluto".

Bunsen era un misógino convencido, tanto que había jurado que jamás una mujer hollaría con su presencia el sagrado recinto de su laboratorio. (La historia no cuenta si la sirvienta entraba alguna vez a quitar el polvo). El bueno de Bunsen no conocía a las mujeres.

En resumen. 
Por aquel entonces vivía en San Petersburgo una joven aristócrata rusa, Sofía (o Sonia) Kowaleusky (o mejor Kowaleuskaya). Esta joven era una estudiosa de la ciencia, de modo que pensó en trasladarse a Alemania para perfeccionar sus conocimientos. En principio, no se le concedió el permiso por ser mujer soltera, de modo que Sofía contrajo matrimonio con un militar y geólogo, Kowaleusky, pero con la condición de no "consumar el matrimonio" hasta que ella regresara de Alemania.

En este país solicitó ser recibida por Bunsen. La aristócrata iba, como correspondía a su clase, elegantemente vestida y se tocaba con un gracioso sombrerito provisto de un velo que le cubría parcialmente los ojos -las crónicas dicen que eran muy bonitos. Bunsen, cortésmente, la recibió pero, cuando Sofía le propuso que le diera clases, empezó con evasivas. Nadie sabe lo que ocurrió, sólo que al final de la entrevista Sofía no llevaba el sombrerito y el químico había claudicado y accedido a darle clases.

Pasado algún tiempo el maestro llegó a la conclusión de que él ya había cumplido pero que Sofía necesitaba ampliar su base matemática, por lo que le sugirió que acudiera a Weierstrass, para quien le dio una carta de recomendación pero, al propio tiempo, escribió otra a matemático que venía a decir más o menos esto:

Estimado colega, unos de estos días le visitará un señorita rusa que ha sido alumna mía para que Vd la instruya. Si usted no está dispuesto a darle clases, por nada del mundo deje que se quite el sombrero.

Con sombrero o sin él, Weierstrass dio clases a la Kowaleuskaya.

Transcurrido el tiempo, ésta regresó a Rusia y, por lo visto, se incorporó a la vida social. Parece ser que sus maestros se enteraron y le escribieron una carta reprochándole que después de lo que habían hecho por ella abandonara la ciencia 
para dedicarse a saraos y otros solaces. Sofía, que enviudó joven, los debió escuchar ya que los dos viejos intentaron que fuera admitida como profesora en el claustro de la Universidad de Heildelberg, pero allí no la aceptaron por ser mujer, por lo que acabó como profesora en la Universidad de Estocolmo, siempre por recomendación y padrinazgo de sus maestros.

Otro gran científico con concomitancias musicales fue Max Planck, quien en algún momento de su vida se planteó la posibilidad de dedicarse profesionalmente a la música, afortunadamente para la Física, su opción fue la ciencia.

Con todo, no es la música clásica única en las aficiones de los físicos. Existe un grupo roquero norteamericano bautizado con el nombre "Panta rei" (expresión griega que significa todo fluye, claramente relacionada con el concepto cosmológico del atomista Demócrito) que está formado por un grupo de astrofísicos.

No me costa de ningún "zarzuelero" que además fuera científico y eso que en el mundo de la zarzuela hay de todo, como el catalán Amadeo Vives (Amadeu, en versión post-Rovira). Vives era un enamorado de Madrid: Barcelona es mi madre, Madrid es mi novia, decía; y a Madrid dedicó la que posiblemente sea su mejor obra "Doña Francisquita". Pues bien, Amadeo Vives tuvo una vida bastante "bohemia" como se decía entonces, de modo que siempre estaba a la quinta pregunta, como se dice todavía hoy.

Justamente el músico tenía un hermano sacerdote, capellán de uno de los manicomios de los aledaños de Madrid, así que, cuando Amadeo andaba bajo mínimos, solía recurrir al socorro de su hermano. En una de las visitas económicas, y justo cuando se retiraba un loquero (no sé la palabra políticamente correcta a utilizar), le tomó por uno de los internos que se fugaba, así que le agarraron: 
- ¡Qué no estoy loco!

- Todos decís lo mismo.

Al final consiguió que llamaran a su hermano y que éste, sin mucho convencimiento de los loqueros, respondiera de su cordura, y le dejaron marchar.

No tiene nada que ver con la física, pero me ha venido a la mente y ahí queda. 